\title{
Comparison of Effects of Quadriceps Versus Short Foot Exercises on Pain and Navicular Drop in Patients with Anterior Knee Pain
}

\section{IJCRR}

Section: Healthcare

ISI Impact Factor

(2020-21): 1.899

IC Value (2020): 91.47

$\operatorname{SJIF}(2020)=7.893$

(c) (i) (8)

Copyright@IJCRR

\section{Khan Seemab ${ }^{1}$, Agrawal Ronika², Siddiqui Misbah ${ }^{3}$}

'Professor, Department of community Physiotherapy-M A Rangoonwala College of Physiotherapy, Pune, M.S., India; 'Principal - M A

Rangoonwala College of Physiotherapy, Pune, M.S., India; ${ }^{3}$ ntern - M A Rangoonwala College of Physiotherapy, Pune, M.S., India.

\section{ABSTRACT}

Introduction: Pronation of foot and reduced medial longitudinal arch (MLA) can result in patellar tracking dysfunction causing anterior knee pain. The treatment protocol commonly includes hip and knee muscle strengthening and patellar taping etc. correcting the biomechanical alignment of the foot by maintaining the MLA height is of great importance in treatment of anterior knee pain.

Aim: To compare the effects of quadriceps exercises versus foot exercises on pain and Navicular drop in patients with anterior knee pain.

Methodology: The 60 subjects were divided into two groups - A and B, where group A was given foot exercises while group $B$ was given knee exercises. Outcome measures were Visual analog scale (VAS), Navicular drop and KOS-ADL score taken before and after six weeks of intervention.

Results: Both the interventions were effective in reducing pain and navicular drop in patients with anterior knee pain.

Conclusion: Better result in Navicular drop was found in subjects given short foot exercises while VAS score and KOS-ADL score improved more in subjects who were given quadriceps exercises.

Key Words: Anterior knee pain, Medial longitudinal arch, Navicular drop, Quadriceps exercise, Short foot exercises, Visual analog scale

\section{INTRODUCTION}

Anterior knee pain is known as knee pain caused by the aberrant motion of the patella in the trochlear groove, which results from biomechanical and/or physical changes within the patellofemoral joint. ${ }^{1}$ There is a strong correlation between pronated foot and reduced MLA therefore anterior knee pain can be prevented by maintaining the integrity of the arch.

Many studies suggest the use of weight-bearing as well as non-weight-bearing quadriceps exercises in the rehabilitation programme of anterior knee pain. ${ }^{2}$

Thus the purpose of this study is to compare the effects of quadriceps exercises versus short foot exercises on pain and navicular drop in patients with anterior knee pain.

\section{METHOD}

After the approval from ethics committee of the institute, subjects having knee pain were screened, 60 subjects meeting the inclusion criteria as having anterior knee pain for at least past 3 months and reported pain in 2 or more daily activities like ascending and descending stairs, squatting, kneeling, jumping and long sitting. pain on palpation of the medial and/or lateral facet of the patella and Navicular drop test more than or equal to $15 \mathrm{~mm}$. patients with any knee pathology, recent injury of lower limb and on any other treatment for anterior knee pain were excluded.

All the subjects were asked to fill a consent form after a thorough explanation of the testing procedure, protocol and training and their doubts and queries were cleared.

\section{Corresponding Author:}

Dr. Seemab Khan, Professor, M A Rangoonwala College of Physiotherapy, Pune, M.S., India.

Mob: 9822676725; Email: drseemabk@gmail.com

ISSN: 2231-2196 (Print)

ISSN: 0975-5241 (Online)

Received: 26.03 .2021

Revised: 19.05 .2021

Accepted: 26.07 .2021

Published: 16.01 .2022 
Subjects were then randomly allocated by chit method in two groups namely- Group A and Group B.

The measurements of the variables i.e. the Visual analogue scale, Navicular drop test and KOS-ADL Scale were taken at the beginning and after 6 weeks of intervention for both the groups.

\section{Outcome measures}

Visual Analogue Scale: The pain severity was documented using the visual analogue scale (VAS). Test-retest reliability is 0.77 and the Validity of it is $0.76^{3}$

Navicular Drop test: Navicular drop can be used to measure the amount of pronation of foot

The ICC validity value for Navicular drop is 0.745 and intraand inter-rater reliability is 0.76 - and $0.84^{4}$

KOS-ADL the Knee Outcome Survey-Activities of Daily Living scale (KOS-ADL) is an instrument that helps to determine the functional ability and disability of the patient.

Validity is 0.89 and Test-retest reliability is $0.94 .^{5}$

\section{Intervention}

Both the groups received the intervention for six sessions per week for 6 weeks.

Ultrasound of $1 \mathrm{MHz}$ with intensity of $1 \mathrm{~W} / \mathrm{cm}^{2}$, continuous mode was given around the anterior knee to both the groups for 6 mins during the first week of the treatment. ${ }^{6}$

Subjects in the Group A were given the short Foot exercises. ${ }^{7,8}$ Subjects in Group B were given Quadriceps exercises. ${ }^{9}, 10$

\section{Table 1: Exercise Protocol for Group A}

\begin{tabular}{|c|c|c|}
\hline Weeks & Exercise & Sets \\
\hline $1^{\text {st }}$ Week & $\begin{array}{l}\text { Toe curl exercises without } \\
\text { resistance } \\
\text { Short foot exercises in } \\
\text { non } \\
\text { weight bearing }\end{array}$ & $\begin{array}{l}25-30 \text { reps * } 3 \text { sets } \\
25-30 \text { reps * } 3 \text { sets }\end{array}$ \\
\hline $2^{\text {nd }} \& 3^{\text {rd }}$ Week & $\begin{array}{l}\text { Toe curl exercises with } \\
\text { resistance } \\
\text { Short foot exercises in } \\
\text { weight bearing }\end{array}$ & $\begin{array}{l}25-30 \text { reps * } 3 \text { sets } \\
25-30 \text { reps * } 3 \text { sets }\end{array}$ \\
\hline $4^{\text {th }}-6^{\text {th }}$ Week & $\begin{array}{l}\text { Toe curl exercises with } \\
\text { resistance } \\
\text { Short foot exercises in } \\
\text { weight bearing } \\
\text { heel raises }\end{array}$ & $\begin{array}{l}25-30 \text { reps * } 3 \text { sets } \\
25-30 \text { reps * } 3 \text { sets } \\
10 \text { reps * } 3 \text { sets }\end{array}$ \\
\hline
\end{tabular}

Table 2: Exercise Protocol for Group B

\begin{tabular}{|c|c|c|}
\hline Weeks & Exercise & Sets \\
\hline${ }^{1 \mathrm{st}}$ Week & $\begin{array}{l}\text { Quadriceps set in pain } \\
\text { free positions } \\
\text { Dynamic quads }\end{array}$ & $\begin{array}{l}10 \text { reps } * 3 \text { sets } \\
10 \text { reps } * 3 \text { sets }\end{array}$ \\
\hline $2^{\text {ndd }} \& 3^{\text {rd } W e e k ~}$ & $\begin{array}{l}\text { Multiple angle isomet- } \\
\text { rics for Quadriceps in } \\
\text { pain free range } \\
\text { Dynamic quads }\end{array}$ & $\begin{array}{l}\text { 10 reps * }{ }^{*} 10 \text { sec } \\
\text { hold }{ }^{*} 3 \text { sets } \\
\text { 1o reps * } 10 \text { sec } \\
\text { hold * } 3 \text { sets }\end{array}$ \\
\hline $4^{\text {th }}-6^{\text {th }}$ Week & $\begin{array}{l}\text { Dynamic quads } \\
\text { Wall Squats } \\
\text { Step down }\end{array}$ & $\begin{array}{l}\text { 10 reps * }{ }^{*} 10 \text { sec } \\
\text { hold }{ }^{*} 3 \text { sets } \\
\text { 10 reps }{ }^{*} 3 \text { sets } \\
10 \text { reps }\end{array}$ \\
\hline
\end{tabular}

\section{Statistical analysis and results}

Statistical analyses were carried out using the Statistical software R studio version 3.6.2. Microsoft word and Excel were used to generate graphs, tables etc.

Results of continuous measurements were presented on Mean \pm SD. Level of significance was fixed at $p=0.05$ and any value less than or equal to 0.05 was considered to be statistically significant.

Within group comparison of visual analogue scale, navicular drop test and knee outcome survey questionnaire was done using Wilcoxon Signed Rank Test, while between group comparison was done using the unpaired $t$ test.

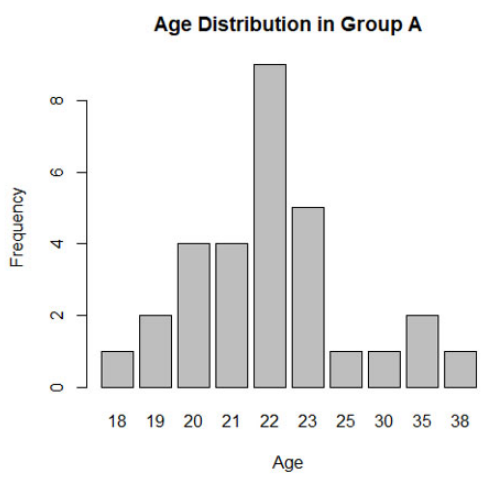

Figure 1

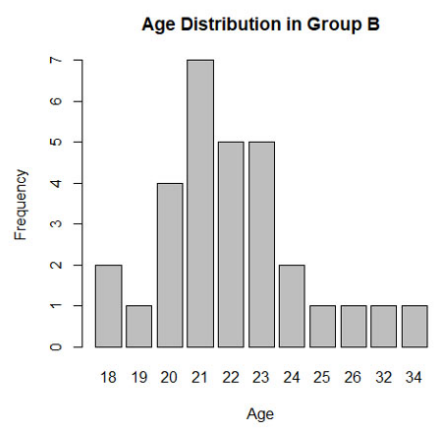

Figure 2 


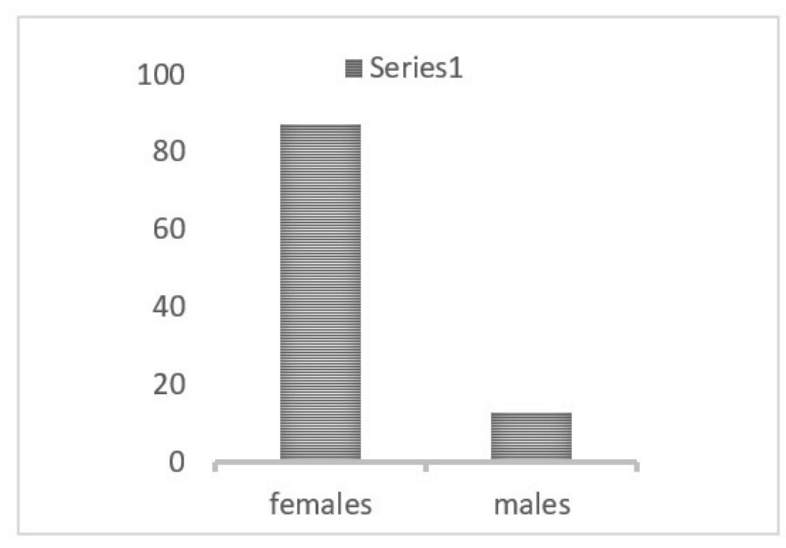

Figure 3: Gender distribution in Group A.

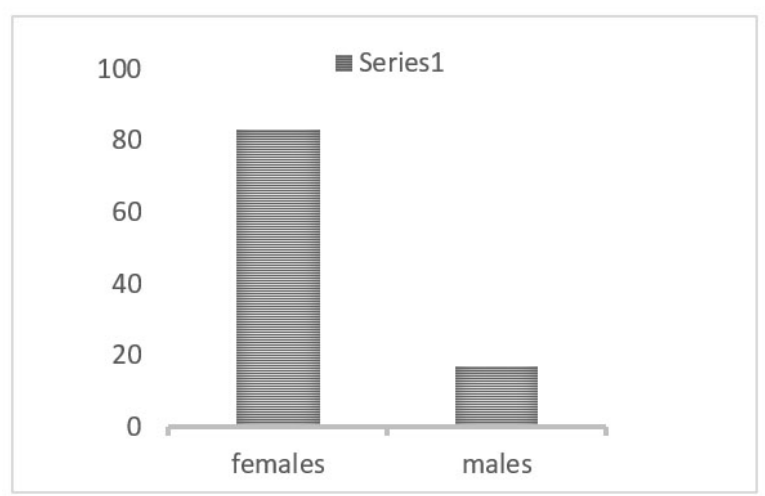

Figure 4: Gender distribution in Group B.

Table 3: Intragroup Comparison of VAS Score, Navicular drop, KOS-ADL Score before and after intervention of Foot exercise using Wilcoxon Signed Rank Test (Group A)

\begin{tabular}{llccc} 
Variable & $\begin{array}{l}\text { Time } \\
\text { Interval }\end{array}$ & Mean & Std Dev. & p-value \\
VAS SCORE & Pre & 5.333 & 0.95893 & ${ }^{*} 7.06 \mathrm{E}^{-07}$ \\
& Post & 1.033 & 0.96431 & \\
\multirow{2}{*}{ NAVICULAR drop } & Pre & 16.9 & 0.80301 & ${ }^{*} 6.95 \mathrm{E}^{-07}$ \\
& & & & \\
\multirow{2}{*}{ KOS-ADL } & Post & 14.73 & 0.82768 & \\
& Pre & 85.51 & 7.18992 & $8^{*} .87 \mathrm{E}^{-07}$ \\
& Post & 93.02 & 4.23044 & \\
\hline
\end{tabular}

"p value $<0.05$

The above table shows pre and post intervention difference in Group A. As p-value is $<0.05$ for all the three variables, it indicates that the VAS Score and Navicular drop have reduced significantly, while KOS.ADLS score has increased significantly after the treatment.
Table 4: Intragroup Comparison of VAS Score, Navicular Drop, KOS.ADLS Score before and after intervention of Knee exercise using Wilcoxon Signed Rank Test (Group B)

\begin{tabular}{lcccc} 
Variable & $\begin{array}{c}\text { Time } \\
\text { Interval }\end{array}$ & Mean & Std Dev & p-value \\
VAS SCORE & Pre & 5.33333 & 1.06134 & ${ }^{*} 6.93 \mathrm{E}^{-07}$ \\
& Post & 0.16667 & 0.37905 & \\
NAVICULAR & Pre & 16.5 & 0.73108 & ${ }^{*} 0.000213$ \\
& Post & 15.9667 & 0.80872 & \\
KOS-ADL & Pre & 79.97 & 9.54283 & ${ }^{*} 9.09 \mathrm{E}^{-07}$ \\
& Post & 95.09 & 3.68897 & \\
\hline
\end{tabular}

"pvalue $<0.05$

The above table shows that $\mathrm{p}$-value $<0.05$ for all the three variables in Group B, it indicates that the VAS Score and Navicular drop have reduced significantly, while KOS.ADLS score has increased significantly after the treatment in Group B.

Table 5: Comparison of VAS Score, Navicular Drop and KOS-ADL Score between both the groups.

\begin{tabular}{lllll} 
Variable & Group & $\begin{array}{l}\text { Mean dif- } \\
\text { ference }\end{array}$ & Std Dev & p-value \\
VAS SCORE & Foot Exercise & 4.3 & 1.05536 & * o.001668 \\
& Knee Exercise & 5.167 & 0.94989 & \\
NAVICULAR & Foot Exercise & 2.16667 & 0.91287 & * $9.51 E^{-09}$ \\
& Knee Exercise & 0.53333 & 0.62881 & \\
KOS-ADL & Foot Exercise & -7.5033 & 5.15896 & * o.001093 \\
& Knee Exercise & -15.12 & 8.88328 & \\
\hline
\end{tabular}

"p value $<0.05$

The above table shows the intergroup comparison of group A and B. This shows that Knee Exercises given to Group B was more effective in reducing pain and improving function as seen in the VAS Score and KOS-ADL Scale. While foot exercises given to Group A was more effective in improving the Navicular Height.

\section{DISCUSSION}

This study aimed to compare the effects of quadriceps exercises versus foot exercises on pain and navicular drop in patients with anterior knee pain. Both group showed improvement in measures after 6 weeks of intervention.

The statistical significance was also due to the healing effects of ultrasound. One of the main effect of ultrasound is acoustic streaming which enhances the flow of particles from one side of a cell membrane to the other, increasing the 
cell permeability which enhances healing and reduces pain and inflammation. ${ }^{6}$

According to table 3 there was statistical significant improvement in VAS, Navicular drop and KOS-ADL score in subjects of Group A.

Exercises like the short foot exercises and toe-curl exercises have shown to improve the strength of intrinsic foot muscles which may help in controlling the excessive pronation at the subtalar joint position during the weight bearing by maintaining the inner arch. This may be useful in reducing pain in PFPS by correcting the malalignment and the biomechanics that were altered due to pronated foot. ${ }^{2}$

Strengthening of intrinsic foot muscles (IFM) by giving short foot exercises increases their activation while walking, which works like an elastic spring to support and maintain the MLA.

It is therefore suggested that effective neuromuscular control of the intrinsic foot muscle is important so as to stabilize the tarsal and metatarsal bones and also to control the pronation of foot. This fine tune control is required for static as well as dynamic control of the MLA during the gait cycle. ${ }^{11}$

Previous study also describes the treatment of anterior knee pain by controlling foot movements, which reduces the pronation in the stance phase of gait, thus reducing internal tibial rotation and improving lower limb biomechanics. Thus the foot exercise were helpful in controlling the pronation of foot and hence correct the mechanics of lower extremity and was effective in reducing pain in subjects with anterior knee pain ${ }^{6}$.

According to Table 4 and there was significant changes seen in VAS score, Navicular drop and KOS-ADL Score in subjects of Group B as well.

One of the major contributors to anterior knee pain is Muscle dysfunction due to improper firing pattern and quadriceps weakness. Alteration in the contact area and pressure distribution is associated with increase in the strength which relieves the excessive stresses over the sensitive areas and helps in relieving pain. This may be due to changes in the muscle because of strength training, which further reduces the future tissue damage. ${ }^{9}$

Similar study was done by another author who suggests that reduction in lateral tracking of patella during postural loading and dynamic actions is important to improve functions, which is achieved by resistance training of $\mathrm{VMO}^{14}$ When the mechanics at the knee is corrected by correcting the patellar tracking with the help of quadriceps muscles activation, weight bearing throughout the lower extremity improves and the pronation at the foot is also reduced.

In a study by Danny M . Pincivero the recruitment efficiency from 10-90 degrees was more for Vastus lateralis, Vastus medialis was from 70-90 degrees and that of Quadriceps femoris is greatest at 90 degrees.$^{12}$

Thus the quadriceps exercise helps in controlling the patellar tracking and is helpful in reducing pain in subjects with anterior knee pain.

When the results of both the groups were compared it was seen that foot exercises that were given to group A was more effective in improving the navicular drop in the subjects as seen in table 5 .

MLA is supported by many structures like plantar calcaneonavicular ligament, extrinsic foot muscles such as tibialis posterior, intrinsic foot muscles (IFM) and plantar fascia. the main function of the MLA is to act as a shock absorber and distribution of the forces during walking. ${ }^{13}$

Janda and VaVrova found that Short Foot exercise helped in strengthening intrinsic muscles of the foot which increased the inner arch of the foot, thereby shortening the longitudinal arch. ${ }^{14}$ Also in a study by Kyoung A Chunga, the navicular drop showed a significant decrease of $5.47 \mathrm{~mm}$ in the group that were given Short foot exercises and $3.93 \mathrm{~mm}$ in the Toe curl exercises ${ }^{15}$

When summarizing the findings of this study, it can be seen that both Short Foot Exercise and Toe Curl Exercise can be used in intrinsic foot muscle training and a significant improvement can be seen in navicular drop in subjects who have been given both these exercises and there was more improvement in Navicular drop in subjects of group A.

Also in table 5, it is evident that there was more significant improvement in VAS score and KOS ADL score in Group B that were given quadriceps exercises.

Quadriceps exercises increases knee muscle strength, which reduces the mechanical stress in the joint, in turn reducing pain and improved functions in subjects with anterior knee pain. Also the strengthening lead to a better motor control which helps in correcting the malposition of patella and improves the biomechanics of the lower limb during the functional activities.

Many authors have studied the association between increasing strength, reduction in pain and improvement in function. ${ }^{16,17}$ This is supported by another author who found the strong correlation between restoring quadriceps muscle strength to improve the function in patients with anterior knee pain. ${ }^{18}$

Most of the weight bearing activities like walking, stair climbing, squatting, etc. are affected because of anterior knee pain which requires the action of quadriceps muscles, thus improving the strength helps in improving the functions of the individuals having anterior knee pain. ${ }^{19,20}$ 
Hence a better result in Visual Analogue scale and KOS-ADL scale was seen in Group B in which the subjects were given Quadriceps exercises as the improvement in the strength of quadriceps lead to improvement in the pain and function of the subjects with anterior knee pain.

\section{Limitations}

Hip musculature tightness and strength was not taken into consideration which can alter the biomechanical alignment of the lower limb and cause anterior knee pain.

\section{Implications}

Treatment programs for patients with anterior knee pain should incorporate strengthening of the foot muscles as well.

\section{CONCLUSION}

Both foot exercise and knee exercise are effective on pain, Navicular drop and KOS-ADL score in subjects with anterior knee pain. But a better result in Navicular drop was found in subjects given foot exercises while more improvement was seen in VAS and KOS-ADL score in subjects that were given knee exercises.

\section{ACKNOWLEDGEMENT}

We are grateful for the support provided by all the subjects, we would also like to acknowledge the scholars whose articles are cited.

Ethical Issue: Ethical clearance was taken from institutional ethics committee, MARCOPT, Pune. Letter noMARCOPAR/05/2771A

\section{Conflict of interest: Nil}

\section{Source of funding: Nil}

\section{REFERENCES}

1. Green ST. Patellofemoral syndrome. J Bodyw Mov Ther. 2005 Jan 1;9(1):16-26.

2. Cheung RT, Ng GY, Chen BF. Association of footwear with patellofemoral pain syndrome in runners. Sports Medicine. 2006 Mar 1;36(3):199-205.

3. Boonstra AM, Schiphorst Preuper HR, Reneman MF, Posthumus JB, Stewart RE. Reliability and validity of the visual analogue scale for disability in patients with chronic musculoskeletal pain. Int J Rehabil Res. 2008 Jun;31(2):165-9. doi: 10.1097/ MRR.0b013e3282fc0f93. PMID: 18467932

4. Rathleff MS, Nielsen RG, Kersting UG. Navicula drop test ad modum Brody: does it show how the foot moves under dynamic conditions? J. Am. Podiatr. Med. Assoc. 2012 Jan;102(1):34-8.

5. Collins NJ, Misra D, Felson DT, Crossley KM, Roos EM. Measures of knee function: International Knee Documentation Committee (IKDC) Subjective Knee Evaluation Form, Knee Injury and Osteoarthritis Outcome Score (KOOS), Knee Injury and Osteoarthritis Outcome Score Physical Function Short Form (KOOS-PS), Knee Outcome Survey Activities of Daily Living Scale (KOS-ADL), Lysholm Knee Scoring Scale, Oxford Knee Score (OKS), Western Ontario and McMaster Universities Osteoarthritis Index (WOMAC), Activity Rating Scale (ARS), and Tegner Activity Score (TAS). Arthritis care \& research. 2011 Nov;63(S11):S208-28.

6. John AT, Rai HR, Kumar V, Jimshad TU. Effect of ultrasound on pain in amateur squash players with patellofemoral pain syndrome. Int. J. Curr. Res. 2015 Oct 1;7(19):26. .

7. Chung KA, Lee E, Lee S. The effect of intrinsic foot muscle training on medial longitudinal arch and ankle stability in patients with chronic ankle sprain accompanied by foot pronation. Physical Therapy Rehabilitation Science. 2016 Jun 30;5(2):7883.

8. Howitt S, Jung S, Hammonds N. Conservative treatment of a tibialis posterior strain in a novice triathlete: a case report. J Can Chiropr Assoc. 2009 Mar;53(1):23.

9. Eapen C, Nayak CD, Zulfeequer CP. Effect of eccentric isotonic quadriceps muscle exercises on patellofemoral pain syndrome: an exploratory pilot study. Asian J Sports Med. 2011 Dec;2(4):227.

10. Chiu JK, Wong YM, Yung PS, Ng GY. The effects of quadriceps strengthening on pain, function, and patellofemoral joint contact area in persons with patellofemoral pain. Am J Phys Med Rehabil. 2012 Feb 1;91(2):98-106.

11. Jam B. Evaluation and retraining of the intrinsic foot muscles for pain syndromes related to abnormal control of pronation. Advanced Physical Therapy Education Institute. 2006 May;21:1-8.

12. Pincivero DM, Salfetnikov Y, Campy RM, Coelho AJ. Angleand gender-specific quadriceps femoris muscle recruitment and knee extensor torque. J. Biomech. 2004 Nov 1;37(11):1689-97.

13. Jam B. Evaluation and retraining of the intrinsic foot muscles for pain syndromes related to abnormal control of pronation. Advanced Physical Therapy Education Institute. 2006 May;21:1-8.

14. Shashi Kumar CG, Syed N, Mohan N. Comparative study of efficacy of vastus medialis obliquus vs rectus femoris using open kinematic and closed kinematic exercises in patellofemoral pain syndrome. Int J Cur Res Rev | Vol 10 .Issue 03 .October 2011, pg 47-54

15. Chung KA, Lee E, Lee $\mathrm{S}$. The effect of intrinsic foot muscle training on medial longitudinal arch and ankle stability in patients with chronic ankle sprain accompanied by foot pronation. Physical Therapy Rehabilitation Science. 2016 Jun 30;5(2):7883.

16. Stiene HA, Brosky T, Reinking MF, Nyland J, Mason MB. A comparison of closed kinetic chain and isokinetic joint isolation exercise in patients with patellofemoral dysfunction. J Orthop Sports Phys Ther. 1996 Sep;24(3):136-41.

17. Sharayu Agre, Ronika Agrawal, Memon F, Ammarah Ravi, Comparing the Effect of Fast Tempo Music and Slow Tempo Music During Aerobic Exercise on Cardiovascular Endurance in Overweight Adolescents. Int J Cur Res Rev March 2021| Vol 13 - Issue 05 •pg 163-166

18. Heintjes EM, Berger M, Bierma-Zeinstra SM, Bernsen RM, Verhaar JA, Koes BW. Exercise therapy for patellofemoral pain syndrome. Cochrane Database of Systematic Reviews. 2003(4).

19. Agrawal R, Alirajpurwala A. To Study the Additional Effect of Aerobic Exercises on Cognitive Behavioral Therapy in Depressed Diabetics. Int J Cur Res Rev| Vol. 2021 Feb;13(03):132.

20. Witvrouw E, Lysens R, Bellemans J, Peers K, Vanderstraeten G. Open versus closed kinetic chain exercises for patellofemoral pain. Am. J. Sports Med. 2000 Sep;28(5):687-94. 